Artículo 7

\title{
EL DESARROLLO SUSTENTABLE COMO RESPONSABILIDAD SOCIAL UNIVERSITARIA EXPERIENCIAS EN LA FAU DE LA UNT
}

-Horacio Saleme Soledad Aráoz.

\author{
Cátedra de Estructuras I - Facultad de Arquitectura y Urbanismo - Universidad Nacional de Tucumán \\ -Tucumán- Argentina- Avda. Roca 1800- C.P. T4000ABS. Tel. 03814107544 hsaleme@herre- \\ ra.unt.edu.ar; solaraoz@hotmail.com
}

Palabras clave: arquitectura, educación, desarrollo sustentable, universidad.

\section{Resumen:}

La Universidad Nacional de Tucumán (UNT) fue inaugurada en 1914. Sus fundadores se alejaron de los modelos tradicionales de entonces latino y napoleónicodando al mundo una nueva concepción de Universidad, volcada a actuar intensamente en el medio que la sustenta.

Fiel a sus consignas, hoy la primera cátedra de Estructuras de la Facultad de Arquitectura y Urbanismo (FAU) de la misma, cumple con las tres funciones básicas propuestas para la Universidad - Docencia, Investigación y Extensión - desarrollando técnicas arquitectónicas sustentables, aplicándolas en la docencia y transfiriéndolas al medio social y productivo en los ámbitos local y nacional.

En este trabajo presentamos los principales aspectos del proyecto fundacional de la UNT, todavia vigentes, y las acciones concretas de esta cátedra. Las más trascendentes en materia de Extensión se desarrollan en fundaciones ecologistas, en la reserva Experimental de Horco Molle de la UNT y en un Complejo Educativo de la localidad de Santa Lucía - Monteros- Tucumán- en las que, además de la transferencia de conocimientos, sistemas y procedimientos, se proyectan y dirigen obras en una escala cada vez mayor. Los materiales y técnicas utilizados garantizan la sustentabilidad de las obras y la sustentabilidad del desarrollo local al generar nuevas alternativas productivas y laborales. Finalmente, se asegura la sustentabilidad del conocimiento, pues los estudiantes de grado y post-grado trabajan generando conocimientos sin repetir viejas lecciones y los participantes de los cursos y talleres no formales incorporan inmediatamente lo aprendido a la resolución de problemas concretos en su medio.

\section{La Universidad de Tucumán:}

Hace 100 años se inauguró la Universidad de Tucumán. Juan B. Terán, su fundador y primer Rector, la presentó como hija de su siglo para servir la misión de su siglo. No repitió ningún molde sino que, surgida en esta tierra, intentaba ser "sintesis de su historia, intérprete de su genio, luz de su conciencia íntima y a la vez ojo abierto dentro de su corazón para escrutarlo y sostenerlo".

Terán y su gente proyectaron una universidad diferente del cuadro tradicional de la universidad latina. Propuso, en una organización flexible y práctica, vincular, penetrar y establecer los más dispares órdenes del conocimiento, los más especulativos con los más prácticos, dando al mundo una idea nueva de universidad.

Uno de sus objetivos básicos fue el estudio del medio natural y cultural en el que se asienta. Antes que nada, quería reconocer, investigar e interpretar nuestra propia naturaleza, pues el conocimiento y aprovechamiento de sus recursos naturales fortaleceria la sociedad con sólidos cimientos para que sea asiento de justicia y libertad.

Su idea central era que por ser hijos de un país determinado y proceder de un pasado concreto, tenemos un destino que debemos perseguir y poseer, en consonancia con los imperativos de nuestro medio y de nuestra historia, ciertos de una misión en la comunidad de las naciones. Veía al Norte Argentino como una unidad 
histórica en la que Tucumán era su centro y quería para la universidad la misión de revelar esa unidad para ser su fuerza y conciencia.

Concibió a la universidad como una obra moral porque pensaba que nada como ella debe propagar fines superiores para la conducta. Juzgaba dificil pensar y sentir bajamente cuando se ha vivido todos los años de la juventud en la pureza y ascetismo del estudio. Consideraba función de la universidad la dirección moral de la sociedad y la difusión de las ideas fuerza que la engrandecian.

\section{Visión social de la Universidad:}

Juan B. Terán propuso, para lograr la alta cultura, la solución previa de los problemas sociales y económicos ya que la actividad artistica y la pura cultura suponen un reposo asegurado por la grandeza material. Buscaba hacer obra social creando estímulos y capacidades efectivas, concordando la enseñanza con las aspiraciones y las necesidades de tiempo y lugar, fortificando ideales de conducta y de acción que evitarian las vocaciones estériles para la sociedad y la frustración de los egresados. Quería que la universidad sea "no un establecimiento educacional más, sino una fundación social, que se correlaciona con un estado de la sociedad, que aspira a un mejoramiento social extenso y supone un sistema de transformaciones sociales".

Esta actitud fue revolucionaria en su tiempo. Toda universidad debe actuar en el medio natural y cultural en el que está inserta, pero a principios del siglo $X X$, muchos pensaban que la universidad era una suerte de campana de cristal donde unos pocos iniciados realizaban su vocación intelectual y cultural sin ensuciarse las manos. Terán juzgó que esta actitud constituía una afligente pedantería basada en el culto del intelectualismo puro, admiración por las ideas y seducción por las formas. Esto generaba universidades solemnemente doctorales pero olvidadas de la realidad del hombre, la sociedad y el medio donde se desarrollaban.

Se propuso ampliar el número de los beneficiados por la Universidad, para lo que juzgó esencial la extensión universitaria - novedosa en ese momento - para educar al adulto y a la mujer. Define esta propuesta una acción difusiva, social y democrática con procedimientos experimentales y prácticos mediante la observación de la naturaleza y el esfuerzo personal.

Valoraba asi el trabajo manual encaminado al aprovechamiento de las materias primas de la región pero sobre todo para desarrollar lo que vale más que cualquier concepto en abstracto: "la destreza de los sentidos y el hábito de la observación exacta".

Resumiendo su propuesta dijo textualmente: "Esa enseñanza que pudiera creerse inimaginativa y utilitaria, es sin embargo la que aviva más intensamente la facultad inventiva y el sentido estético, porque la naturaleza, complicada y aparentemente caprichosa, sugiere la posibilidad de las relaciones más inesperadas entre los fenómenos, que es la invención misma, y es además fuera de toda duda, la maestra eterna y única del sentimiento estético".

\section{La Universidad hoy:}

La Universidad sufre todos los males que sufre el país. ¿Qué nos llevó desde el quinto lugar entre las naciones de la tierra al nonagésimo que ocupamos hoy? Dirigismo estatal, sobredimensionamiento administrativo, burocratización, facilismo, politización partidista, pauperización institucional y docente, entre otros, son los males que la esclerosan.

Hoy las universidades argentinas rara vez cumplen en plenitud sus tres objetivos básicos: Docencia, Investigación y Extensión, a pesar de ser axioma básico incuestionado que no se puede hablar de universidad sin cubrir estas tres funciones. Las universidades del estado por los niveles de politización que llevaron a la masificación irracional y las privadas por los altos costos de la investigación - particularmente la tecnológica - son fundamentalmente lugares para obtener títulos más que centros de generación de conocimientos. Los tres factores interactivos que condicionan el quehacer universitario sonpolitica, economía y sociedad. Ignorar estas relaciones no permite ver la realidad, pues no existe profesión que pueda prosperar en el aislamiento de laboratorios, aulas o bibliotecas. Por ello, el primer objetivo de la educación superior debe ser preparar a mujeres y hombres concretos para actuar en su medio. Esto supone una integración de saberes que permita la maduración de nuestra compleja y polifacética naturaleza para que el egresado perciba las necesidades y los valores del lugar donde interviene, y no la deformante y alienante hiperespecialización que caracteriza a nuestra cultura postmoderna.

La noción del conocimiento como bien social está en crisis. El mercantilismo dominante va imponiendo sus valores (o desvalores) desde que lo que determina las politicas universitarias son parámetros exclusivamente 
crematísticos en los que se desecha cualquier otro objetivo que no sea el consumo. Este fenómeno es global y, como tal, nos afecta también.La gran demanda en algunas áreas del conocimiento llevó a muchas universidades a diseñar sus propuestas sólo en función de ese mercado, en desmedro de la calidad, la pertinencia y la universalidad de la cultura que hacen a la esencia misma de la universidad. No se puede actuar así sin gravísimas consecuencias. Si el fin de la educación superior es la Cultura, con mayúsculas, respetando las particularidades regionales y su identidad, la comercialización del saber con la pérdida de un genuino humanismo integrador puede resultar fatal.

humanismo integrador puede resultar fatal.

La crisis de una educación superior que pasa de bien social a mercancía ya estaba latente hace cien años y Terán supo verla con una lucidez que sorprende cada día más. Todo su genio queda evidenciado en el lema que adoptó para la Universidad de Tucumán: Pedes in terra ad sideravisus.Los pies en la tierra, la mirada al cielo.

Hace a ese espíritu formar a los estudiantes para que, el dia de mañana continúen la tarea de preservar y aumentar patrimonio de la sociedad de la que recibieron todo. Para lograr el bien social que representa la educación, el universitario necesita impregnarse de las tradiciones y del espíritu de su comunidad, es decir, ser consciente de sus circunstancias histórico-sociales, lo que no significa aislarse del resto del mundo.

En su libro La Salud de la América Española², Terán registra sin atenuantes los malos pasos de la historia de nuestra América, pero al mismo tiempo nos alienta a pensar que son superables. Acierta con agudeza cuando señala que la clave hemos de encontrarla en la educación y en la cultura.

Desde que su función propia es la enseñanza, la investigación, y los servicios que debe prestar al conjunto de la sociedad, en adelante será juzgada no sólo por el cumplimiento más o menos prolijo de sus funciones especificas sino también por su independencia de criterio y por su contribución a la reflexión crítica y a la solución de los grandes problemas y necesidades de la sociedad a la cual se debe.

El historiador Luis Alberto Romero señala en un articu$10^{3}$ que la universidad argentina - heredera de la Reforma del 18 - exhibe tantas luces y sombras comola de- mocrácia. En su momento -dice- la Reforma planteó de manera novedosa el papel de la universidad en una sociedad democrática. Buscaba la inclusión, la renovación de las ideas y la reflexión sobre la sociedad y sus problemas. Esto se tradujo en algunos principios fuertes, como el concurso, el cogobierno y el ingreso libre, fórmulas que hoy son una suerte de tabú que impide discutir los nuevos problemas.

Concluye que el mensaje de la Reforma sobre la democracia es hoy ambiguo: por un lado, una incitación a la transformación ordenada y reflexiva y por otro, la adhesión literal a sus formulaciones históricas. Romero termina diciendo que quienes como él, se sienten -aunque "un poco incómodos"- herederos de la Reforma, deberian atreverse a revisar sus premisas, apartándose de la letra para recuperar su espiritu.

\section{Una Cátedra de la FAU de la UNT:}

En este marco, la Cátedra de Estructuras I de la Facultad de Arquitectura y Urbanismo de la UNT desarrolla en confluencia con la docencia, variadas actividades de investigación y extensión buscando coadyuvar al desarrollo sustentable en el campo tecnológico arquitectónico, habida cuenta de que la industria de la construcción incide en más de un $40 \%$ en el calentamiento global, tanto en el proceso de obra como durante la vida útil de los edificios y ciudades.

Para ello, desde la enseñanza misma de las técnicas y sistemas estructurales y constructivos se presenta la problemática ambiental y, en función de esa realidad, cuales son los caminos más apropiados para disminuir y minimizar ese fenómeno que compromete la vida misma del planeta, nuestra única casa.

Las nuevas Técnicas de la Información y la Comunicación - ineludibles en este tercer milenio - han creado en los ámbitos universitarios una sobrevaloración de sus aplicaciones en la etapa de formación y desarrollo técnico. A tal punto que se habla de "realidad virtual" $\left.\right|_{0}$ que constituye per se una contradictio in terminis, pues lo real no es virtual y lo virtual no es real. Se trata sí de aprovechar las nuevas técnicas como valiosos instrumentos operativos sin descuidar la educación y el desarrollo de la creatividad actuando, desde el comienzo, en el medio donde el futuro egresado habrá de ejercer su profesión.

En la cátedra presentamos los procesos de investigación tecnológica, su aplicación en la docencia en base

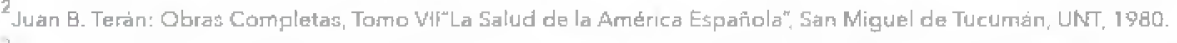

"Romero, Luis Alberto: "La Unversidad de la democracia y el legado de la Reforma", Griterio No 2383 - Julio de 2012. 
a realidades tangibles y no teoréticas, su utilización en casos concretos del medio natural y cultural y su transferencia a diversas entidades educativas y sociales, cubriendo todas las escalas de la educación formal e informal, en variados ámbitos del pais y del extranjero. Se trabaja para ello con estudiantes y docentes, partiendo de problemas específicos en el marco de la problemática económico-social, contribuyendo no tan sólo al mejoramiento de la educación sino estimulando la creatividad y promoviendo la generación de alternativas productivas novedosas. Si esto se generaliza, lograremos una genuina educación para el desarrollo integral.

En sintesis se presentan:

- Los Métodos de Enseñanza de los sistemas y técnicas arquitectónico-estructurales en función de realidades del medio, desarrollados en la misma universidad y en variados ámbitos educativos. -La Investigación Tecnológica en la búsqueda de opciones que minimicen el impacto ambiental, para asegurar la sustentabilidad del desarrollo.

- La Transferencia Educativa y Técnica a diversos organismos estatales, paraestatales y privados (ONGs, fundaciones, colegios de nivel primario y medio, institutos terciarios etc.), promoviendo alternativas productivas para generar nuevas fuentes de trabajo en especial en zonas rurales, contribuyendo a una genuina y sustentable promoción social que evite la migración campo-ciudad.

\section{De la Enseñanza Tecnológica:}

Desde el punto de vista metodológico, el proceso de enseñanza-aprendizaje en el campo de la tecnologia, hace tiempo ha hecho crisis en nuestras universidades. En tal sentido no puede basarse la enseñanza en formulaciones teoréticas o en "modelos" que no siempre responden a la realidad.

En el campo de la técnica, es necesario insistir en la heuristica (en el sentido de "arte de inventar") - como lo enseñaba Eduardo Torroja" - más que en teorias, preconceptos o recetas, que pueden perder vigencia antes de la graduación del estudiante.

La masividad estudiantil, por otra parte, ha condicionado los procesos de enseñanza- aprendizaje, imponiendo a veces un camino puramente teórico, que no llega al "hacer", objetivo fundamental de toda técnica. Se accede al grado, muchas veces, conociendo solamente lo que hacen otros, sin haber experimentado personal- mente un proceso tecnológico. En el mejor de los casos se termina en Proyecto, sin llegar a la realización.

Por superar esto la Cátedra ha implementado, desde su constitución, una articulación permanente entre docencia e investigación.

Con la inserción de grupos interdisciplinarios en poblaciones rurales de la Provincia, la U.N.T. busca unir sus conocimientos científicos y técnicos a la experiencia de vida de sus pobladores, beneficiando y permitiendo crecer, tanto a la comunidad rural como a la universitaria, al posibilitar un replanteo de sus planes de Investigación y de Docencia, basados en el conocimiento de la realidad, humana, geográfica, económica y cultural. En este marco, dentro del área de arquitectura, la cátedra comenzó a investigar las técnicas constructivas utilizadas a nivel espontáneo y popular, a partir de las cuales se puede innovar aprovechando y optimizando los materiales y conocimientos previos disponibles en cada lugar donde la universidad realiza trabajos de extensión o de promoción comunitaria.Hecho esto, se articulan esos métodos en Planes de Docencia para todos los niveles y modalidades educativas.

En sintesis, desde que la preocupación por la región fue el "leitmotiv" de la Generación del Centenario - de la que formó parte Juan B. Terán - sus objetivos fundacionales para la U.N.T. y las propuestas heurísticas de Eduardo Torroja, constituyen los fundamentos metodológicos de este modus operandi educativo.

\section{De la investigación técnica. Objetivos:}

La Arquitectura Sustentable, también conocida como Arquitectura Verde, Eco-arquitectura y Arquitectura ambientalmente consciente, es un modo de concebir el diseño arquitectónico buscando aprovechar los recursos naturales de tal modo de minimizar el impacto ambiental de las construcciones sobre el medio natural y sobre los habitantesa partir de la eficacia y moderación en el uso de materiales de construcción, del consumo de energía y del espacio construido.

La arquitectura genera un gran impacto social en la población y buenos ejemplos en cada comunidad local son necesarios para mostrar los caminos a seguir. En todas las culturas, a lo largo del tiempo surgieron nuevos tipos edificatorios pero solo algunos se convirtieron en modelos para ser repetidos por la sociedad. Mientras en Estados Unidos de Norte América son usuales las casas de construcción liviana (10 a 150 $\mathrm{kg} / \mathrm{m} 2$ ), en América 
del Sur son mayoritariamente de construcción pesada (200 kg/m2). Los materiales y modos de construcción son diferentes probablemente por la cultura que trajo cada tipo arquitectónico. Dado que los cambios en las costumbres no son sencillos, se requieren de enormes esfuerzos para generar alternativas válidas que sean adoptadas masivamente.

Aqui entran conceptos tales como cuál es el costo inicial de un edificio, cuál es el costo a lo largo de su vida útil (estimada en 30 a 50 años). ¿puede una familia o una sociedad pagar dichos costos? ¿Puede afrontarse el costo ambiental?Son todas preguntas que cada sociedad local debe responder y la dirigencia debe dar respuestas adecuadas y sustentables.Todo esto supone un profundo conocimiento del medio a través de la investigación de su realidad material, cultural, geográfica y social.

Para ello la Cátedra se propuso:

- Iniciar en la investigación a estudiantes de grado y post-grado como un modo de promover la creatividad en el campo de las técnicas, desarrollando métodos de trabajo para la actualización permanente.XPromover el intercambio de experiencias de estudiantes de grado y de postgrado en el marco de los convenios suscriptos y a suscribir por la UNT. -Desarrollar alternativas de educación técnica para todos los niveles de la educación formal e informal, no como mero entrenamiento, sino como proceso heurístico o "arte de inventar", asumiendo la educación como "espacio creativo". -Promover el pensamiento reflexivo para encarar nuevas alternativas de educación, producción y desarrollo, mediante la interrelación de todos los conocimientos -incluso los humanísticos - como un modo de comprendery aprehender la realidad.

-Fortalecer la unidad de pensamiento y vida, para conquistar un sistema de enseñanza que otorgue incentivos apropiados a todos los protagonistas del hecho educativo, de tal modo que los valores sean condiciones del encuentro, y permitan desarrollar la personalidad de cada uno.

- Difundir métodos de Desarrollo Técnico Sostenible ante organismos estatales, paraestatales, comunitarios y ONGs a fin de promover alternativas productivas que coadyuven al Desarrollo Sustentable.

-Transferir metodologías de Investigación y Trabajo a otras Universidades e instituciones nacionales.

\section{La Transferencia del Conocimiento y de la Técnicas Sustentables:}

Prácticamente todos los trabajos de la Cátedra surgieron de requerimientos del medio. Para el caso de las construcciones con bambú, por ejemplo, su estudio comenzó hace veinte años a pedido del Proyecto Universitario de Promoción Comunitaria (PUPC) de la misma UNT, en la búsqueda de Técnicas Apropiadas para una Arquitectura Sismorresistente.

Dado que la educación tecnológica a todos los niveles es el gran objetivo de nuestro trabajo académico, es la Transferencia Educativa y Técnica la principal herramienta operativa de la Extensión.

Además de variados cursos, se llevan a cabo talleres:

-En el ámbito universitario nacional e internacional, a niveles de grado y de postgrado en nuestra universidad.Educación Tecnológica, Nuevos Procedimientos y Técnicas Constructivas son los dos grandes rubros que se trabajan.

-A nivel Educación Terciaria, mediante la participación de sus miembros en Postitulos en el marco de la educación rural, como un modo de frenar el despoblamiento del campo y la generación de bolsones de miseria en las ciudades, dando a los profesores una formación técnica y ambiental suficiente para que sean consejeros escuchados por la población y por las autoridades regionales y comunales.

-En idéntico sentido, en Municipios del interior, comunas rurales, ONGs, Cooperativas y entidades del Gobierno, a través de cursos especiales para la formación de técnicos menores (intermedios entre los obreros capacitados y los profesionales universitarios), y cursos de perfeccionamiento de obreros adultos.

Para la difusión de las actividades se utilizan todos los medios que las nuevas técnicas de la comunicación y la información brindan, además de las publicaciones clásicas. Procesos Educativos, Procesos Tecnológicos y Desarrollo de la Creatividad son los temas recurrentes, que la actual crisis educativa y social impone. Todo esto se articula con los sucesivos Proyectos de Investigación, que con variadas fuentes de financiación lleva adelante la cátedra. Se transfieren tanto procesos técnico-arquitectónicos como educativo-arquitectónicos. 


\section{Úlłimas experiencias:}

-Congresos Internacionales de Turismo y Arquitectura Sustentable $(2007,2008,2009$ y 2010) Ministerio de Turismo. Formosa Seminario Taller en Salsipuedes Córdoba Curso-Taller Fundación Gaia en Navarro- Bs As.

-Capacitación para obreros y técnicos en la Reserva Experimental de Horco Molle (REHM), Facultad de Ciencias Naturales de la UNT, Tucumán.

-Seminarios y Talleres en Institutos primarios y secundarios de la enseñanza básica. Proyecto, Dirección Técnica y Talleres para la Obra Popular Educativa Sagrada Familia. Colegio Nuestra Señora de la Esperanza- Sta. LucíaMonteros - Tucumán. (2011 -2014)

-Talleres en la Facultad de Arquitectura, Planeamiento y Diseño de la Universidad Nacional de Rosario.(2013).

-Talleres en la Dirección Provincial de Islas de la Pcia de Buenos Aires. (2013-2014).
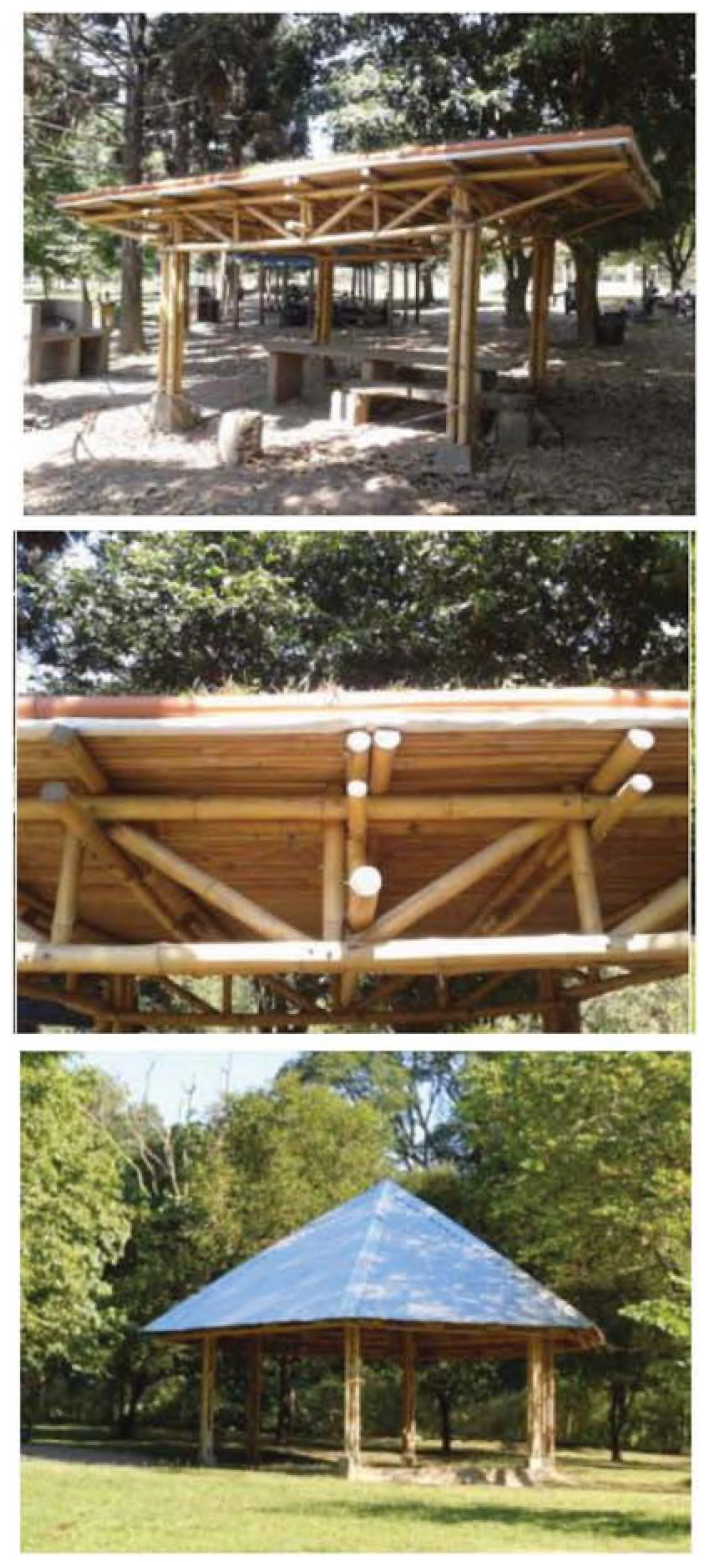

Figura 1:Reserva experımental de Horco Molle. Yerba buena. Tueumán. Fuente: Horacio Saleme
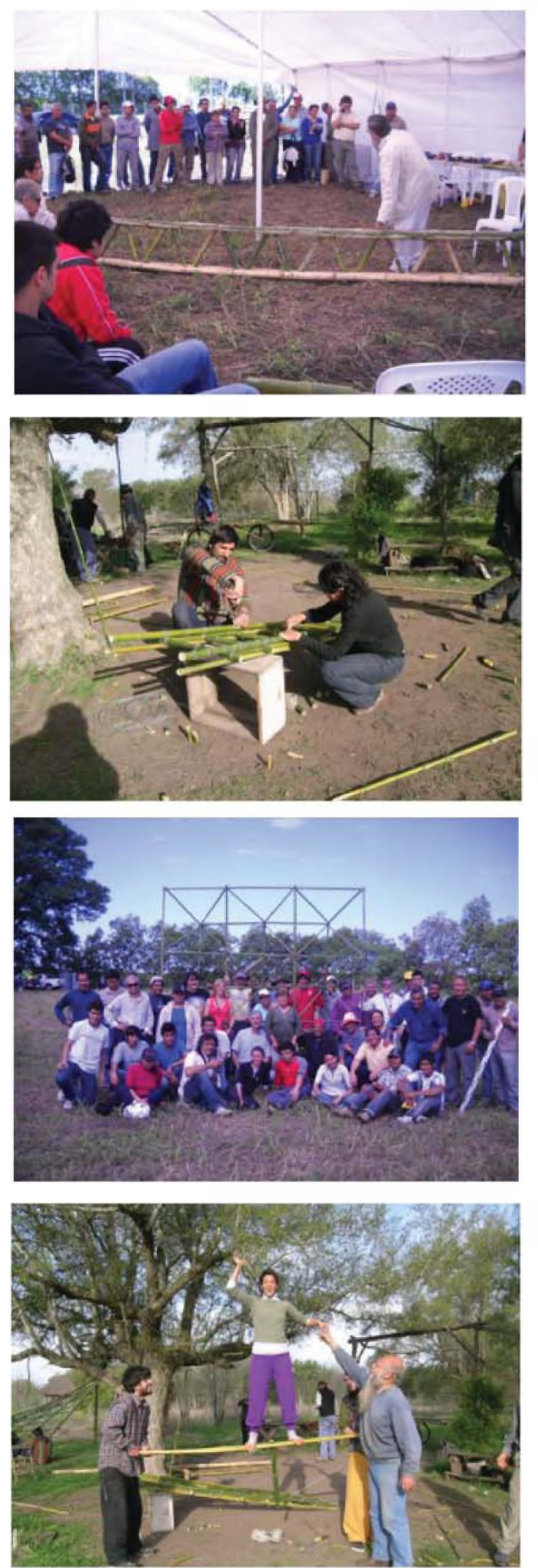

Figura : Capactaciones y talleres.

Fuente: Horacio Saleme

De todas estas acciones, las que se han concretado en obras permanentes para su aprovechamiento, realizadas con proyecto y dirección de la Cátedra, además de los prototipos construidos la misma Facultad, son las de la Reserva Experimental de Horco Molle y las del Colegio en Santa Lucía.

La Obra Popular Educativa Sagrada Familia - OPESaFa - 
está llevando a cabo en la localidad de Santa Lucía, ubicada sobre la Ruta Provincial no 307, aproximadamente a $50 \mathrm{~km}$. de San Miguel de Tucumán un importante emprendimiento comunitario en clave de educación popular. Su objetivo es la promoción de un nuevo orden social, basado en la educación formal e informal, siguiendo el espíritu del pedagogo brasileño Paulo Freire, quien fue uno de los mayores y más significativos pedagogos del siglo $X X$. Sus ideas influenciaron e influencian los procesos democráticos por todo el mundo, fue el "pedagogo de los oprimidos" y en su trabajo transmitió la "pedagogía de la esperanza". Las ideas de Freire son totalmente compatibles con las del espiritu fundacional de la UNT explicitadas, muchos años antes, por Juan B. Terán en el libro "La Universidad y la Vida", en un contexto y circunstancias diferentes.

En este marco se ha suscripto un Acta-Acuerdo entre el "Proyecto Bambü" de la Facultad de Arquitectura y OPESaFa, a efectos de desarrollar el proyecto edilicio, la capacitación del personal técnicoy obrero y la dirección de las obras.

Las construcciones se plantearon en una sola planta. En su etapa final, este Centro Educativo dispondrá de $3.558 \mathrm{~m} 2$-aproximadamente $2850 \mathrm{~m} 2$ cubiertos y 800 $\mathrm{m} 2$ de espacios semicubiertos- constituyendo varios volúmenes funcionales, tales como aulas, talleres, administración, S.U.M., capilla, hospedería, vivienda encargado, locales y espacios auxiliares. El material constructivo fundamental es el Bambú, aprovechando su abundancia en la zona, para lo que se utilizan las técnicas y procedimientos constructivos desarrollados en la Cátedra.

En Octubre de 2011 comenzó la capacitación de obreros de la zona, quienes fueron incorporados a la ejecución del Centro. Realizado este primer taller, la capacitación se extiende a lo largo de todo el proceso constructivo.

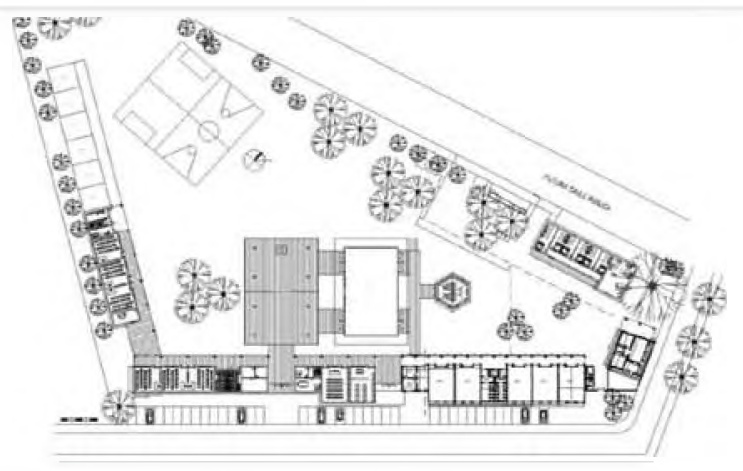

Figura 3: Reserva expermental de Horco Molle. Yerba buena. Tucuman. Fuente: Horacio Saleme
La primera etapa de las obras comenzó el 15 de diciembre de 2011 e incluia la casa del encargado, un pabellón de aulas y locales auxiliares.En marzo de 2012, se concluyó la vivienda y se habilitó para uso escolar. Se destinó como aula el espacio previsto para estar-comedor y cocina y como oficinas de rectoria los correspondientes a los futuros dormitorios, más un núcleo sanitario para alumnos. A ello hay que agregar las canchas del sector deportivo.En los doce meses subsiguientes, se construyeron un aula y otros dos núcleos sanitarios, incluyendo uno para minusválidos.Durante 2013 se edificaron dos aulas más y las oficinas de rectoria, que quedaron habilitadas en marzo de 2014.

A pesar de que las técnicas utilizadas posibilitan un ritmo de obra muy acelerado - como quedó demostrado en la construcción de la casa (cuatro meses) - los avances ulteriores fueron más lentos por razones económicas. إLa vivienda del encargado continúa en uso escolar. Actualmente funciona alli la biblioteca y oficinas de maestros y profesores. Desde 2014 hasta la fecha, se sumaron anualmente un aula o taller, acompa ñando el avance de los estudiantes y una ermita que apoya el carácter religioso del establecimiento.
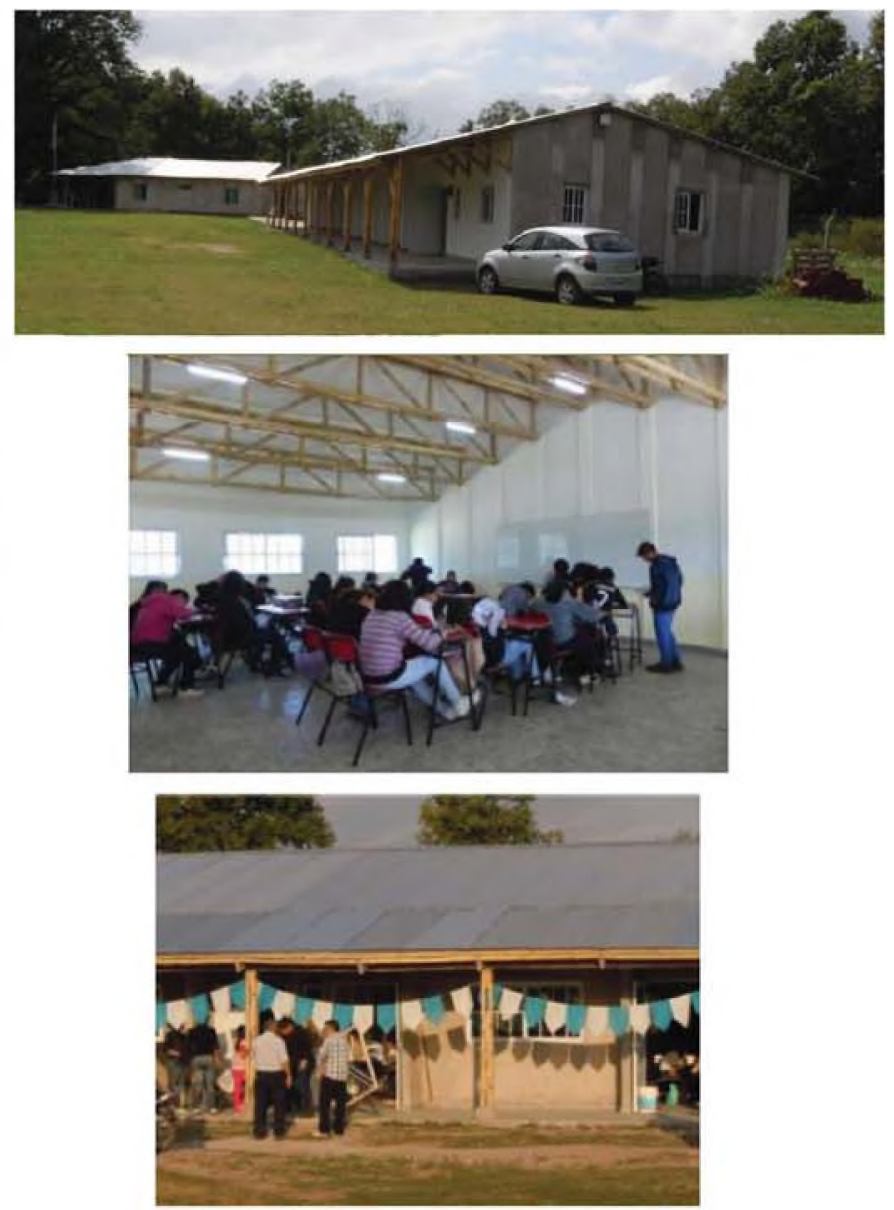

Figura 4: Colegio Maria de la Esperanza -Santa Lucia - Monteros - Tucumán. Fuente: Horacio Saleme 


\section{AT | Revista ARQUITECNO | N8}

\section{Conclusiones:}

El pensamiento de Terán constituye un patrón a partir del cual podemos desarrollar nuestra autocritica, para intentar revertir la actual situación universitaria en todo lo que esté a nuestro alcance e ilustrar a quienes tienen responsabilidades políticas, para crear las condiciones que permitan a la universidad recuperar en plenitud su rol de conciencia crítica de la Nación, creadora de ciencia y tecnologia y formadora de dirigentes, asumiendo en plenitud su ineludible compromiso social.

En el marco de un proyecto educativo, hay que enseñar a pensar bien. No basta con transmitir contenidos. Así como en su vida la persona es un ser en relación, esa naturaleza relacional también es fundamental en el proceso educativo. Relacionar al estudiante universitario con la realidad humana, económica y social del medio que lo sustenta es lo más relevante que se puede hacer desde la educación formal.

La creatividad no es patrimonio de los genios, sino una forma de vivir la vida. Si bien se relaciona esa palabra con la genialidad, es necesario ubicarla en su real dimensión. La educación es el espacio creativo por antonomasia. Hoy no basta con enseñarles contenidos a los jóvenes: tienen que aprender a encontrarlos. Hay que estimular el descubrimiento de los saberes. Para esto hay que ser muy creativos, porque es mucho más difícil serlo que saber algo y limitarse a transmitirlo.

Aprovechar esa experiencia para ampliar la educación y con ella la formación y la inclusión social a todos los niveles es cumplir acabadamente con la razón y ser de las universidades públicas. Así entendemos y así implementamos la Educación para el Desarrollo. Transfiriendo técnicas sustentables para la construcción del hábitat apostamos al futuro siendo fieles al espíritu fundacional nuestra universidad pues, como decía Gaudi" "la verdadera originalidad es la vuelta a los orígenes". Luchar contra la fatalidad es el gran desafío del quehacer argentino, en particular de la universidad. La forma: la Promoción de la Inteligencia, como en su momento lo propuso Juan B. Terán. $\Omega$

\section{Referencias:}

-KREIBOHM, Enrique. Un siglo de cultura Provinciana. San Miguel de Tucumán: UNT. 1960, p.114-118.

-ROMERO, Luis Alberto. La Universidad de la democracia y el legado de la Reforma. Criterio, 2012, No 2383.

-TERAN, Juan B. Obras Completas, Tomo V. La Universidad y la Vida. San Miguel de Tucumán: UNT 1980. 24 p. -TERÁN, Juan B. Obras Completas, Tomo VII. La Salud de la América Española.San Miguel de Tucumán: UNT, 1980. 